\title{
THE LOST INDIAN CHANDRAYAAN 2 LANDER VIKRAM AND ROVER PRAGYAAN FOUND INTACT IN SINGLE PIECE ON THE MOON
}

\author{
Jag Mohan Saxena ${ }^{1}$ iD, H M Saxena $^{* 2}$ (iD , Priyanka Saxena ${ }^{3} \boldsymbol{B}$ (iD \\ ${ }^{1}$ Bldg. 1-E-19, Jai Narayan Vyas Nagar, Bikaner 334003, India \\ *2 Geetanjali Aptts. 9FF, E Block, Rishi Nagar, Ludhiana 141001, India \\ ${ }^{3}$ Indian Institute of Technology, Jodhpur 342037, India
}

DOI: https://doi.org/10.29121/granthaalayah.v8.i12.2020.2608

Article Type: Research Article

Article Citation: Jag Mohan Saxena, H M Saxena, and Priyanka Saxena. (2020). THE LOST INDIAN CHANDRAYAAN 2 LANDER VIKRAM AND ROVER PRAGYAAN FOUND INTACT IN SINGLE PIECE ON THE MOON. International Journal of Research -GRANTHAALAYAH, 8(12), 103-109.

https://doi.org/10.29121/granthaa layah.v8.i12.2020.2608

Received Date: 29 November 2020

Accepted Date: 26 December 2020

Keywords:

Indian Moon Mission

Chandrayaan 2

Lunar Lander Vikram

Lunar Rover Pragyaan

Lander

Rover

\section{ABSTRACT}

The Lunar Lander Vikram of the Moon Mission Chandrayaan 2 of the Indian Space Research Organization (ISRO) lost communication with the Lunar Orbiter and the mission control nearly $2.1 \mathrm{kms}$ above the lunar surface during its landing on the Moon on 7th September, 2019. The exact location and the sight of the lost lander and rover are still elusive. We present here the exact location and first images of the lander Vikram and rover Pragyaan sighted on the lunar surface. It is evident from the processed images that the lander was intact and in single piece on landing away from the scheduled site and its ramp was deployed to successfully release the rover Pragyan on to the lunar surface. This contradicts earlier reports that the lander was disintegrated into small pieces and debris which were scattered far away from the proposed landing site.

\section{INTRODUCTION}

The Lunar Lander Vikram of The Indian Moon Mission Chandrayaan 2 of the Indian Space Research Organization (Isro) Was Scheduled to Land on High Plains Between Two Craters Manzinus C and Simpelius N on A Site At $70.9^{\circ}$ South And $22.7^{\circ}$ East on The South Pole. However, It Lost Communication with The Lunar Orbiter and The Mission Control [1] At 2.1 Kms Above the Lunar Surface During the Last Few Minutes of Its Landing on The Moon On 7th September, 2019. Since Then, A Large Number of Attempts Have Been Made to Locate the Lost Lander and To ReEstablish Contact with It. Even Though Claims of Finding the Lander Have Been Made by The Isro, Nasa And Several Other Organizations, Scientists and Enthusiasts, None Has Been Able to Survive the Scrutiny and Convince the 
Skeptics. We Present Here the First Clear Cut Image of The Lunar Lander Vikram Lying Intact in A Single Piece on The Lunar Surface Spotted by Us On The Authentic Images Of The Moon.

\section{MATERIALS AND METHODS}

The imagery provided by the Lunar Reconnaissance Orbiter (LRO) of NASA on the website hosted by the Arizona State University was scanned visually and the screenshots of the selected images were enlarged and processed by dehazing and enhancing contrast employing MATLAB (MathWorks Inc.).

\section{RESULTS AND DISCUSSIONS}

We have located the position of the lander with respect to the crater Simpelius N (Figs. 1 to 4). In one set of images posted on the LROC website [2], we could see the upwardly tilted intact lander as if ascending a raised slopy surface (Fig. 5a \& b). In another set of images taken at a different time by the LRO, we spotted the intact lander in a straight position at latitude of -69.58650 and a longitude of 23.77852 at $0.50 \mathrm{~m} /$ px. (Figs. 6a \& b). It may be pointed out that Vikram was designed to safely land on slopes up to $12^{\circ}$.

The processing of the image of the lander for dehazing and enhancement of contrast by MATLAB gave valuable clues to its identity (Figs. $5 \mathrm{a} \& \mathrm{~b}, 6 \mathrm{a} \& \mathrm{~b}, 7 \mathrm{a} \& \mathrm{~b}$ ) as we could visualize the rectangular shape of the lander, its top dome like structure, unfolded ramp and the opened door for the release of the rover Pragyan on the lunar surface. Even some of the thrusters at the bottom of the lander could be visible (Figs. 7b, 8). On scanning the LROC images displayed on its website on 1 September, 2020, we could spot the lander Vikram at a latitude of -69.58650 and a longitude of 23.77852 and rover Pragyaan at a latitude of -69.58382 and a longitude of 23.75958 , respectively at $0.50 \mathrm{~m} / \mathrm{px}$ (Figs. $9 \& 10$ ). It may be noted that these sites are distant from the scheduled landing site.

In an image (M1325822321RE) acquired by LROC on 15 October, 2019 at 23:44:14.506 (image type NACR, Orbit 46427 EDR) we could visualize several meters long and wide vertical column of smoke or regolith (or possibly even water) emanating from the vicinity of the lander (Fig. 11.) which might have arisen due to some explosion or impact of some meteorite on the lunar surface.

However, this could not be due to crash landing of Vikram because it was not seen in the images taken immediately after the landing but was noticed in the image taken after one month of landing.

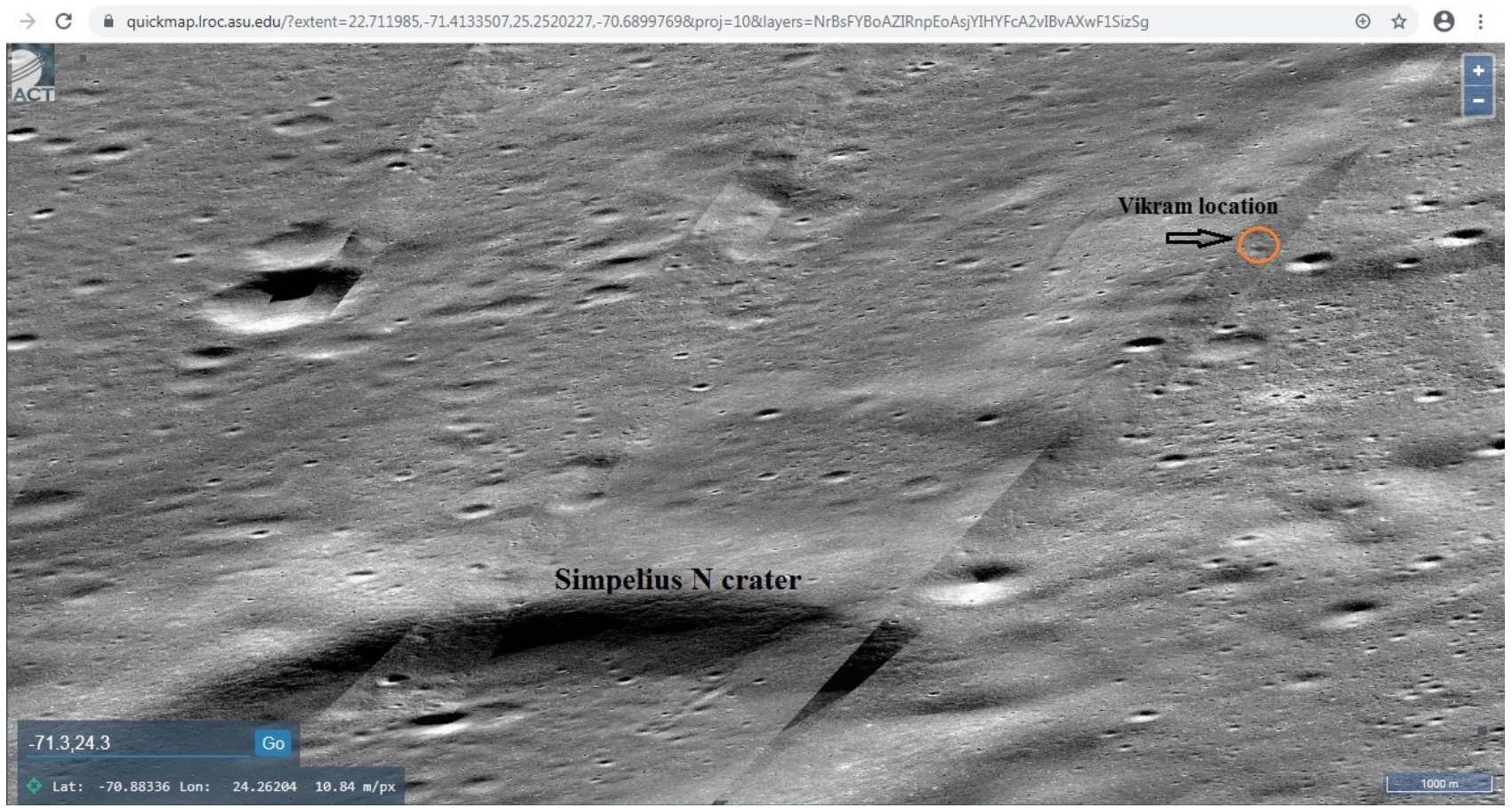

Figure 1: Location of Lunar Lander Vikram from the Simpelius N crater on the Moon 


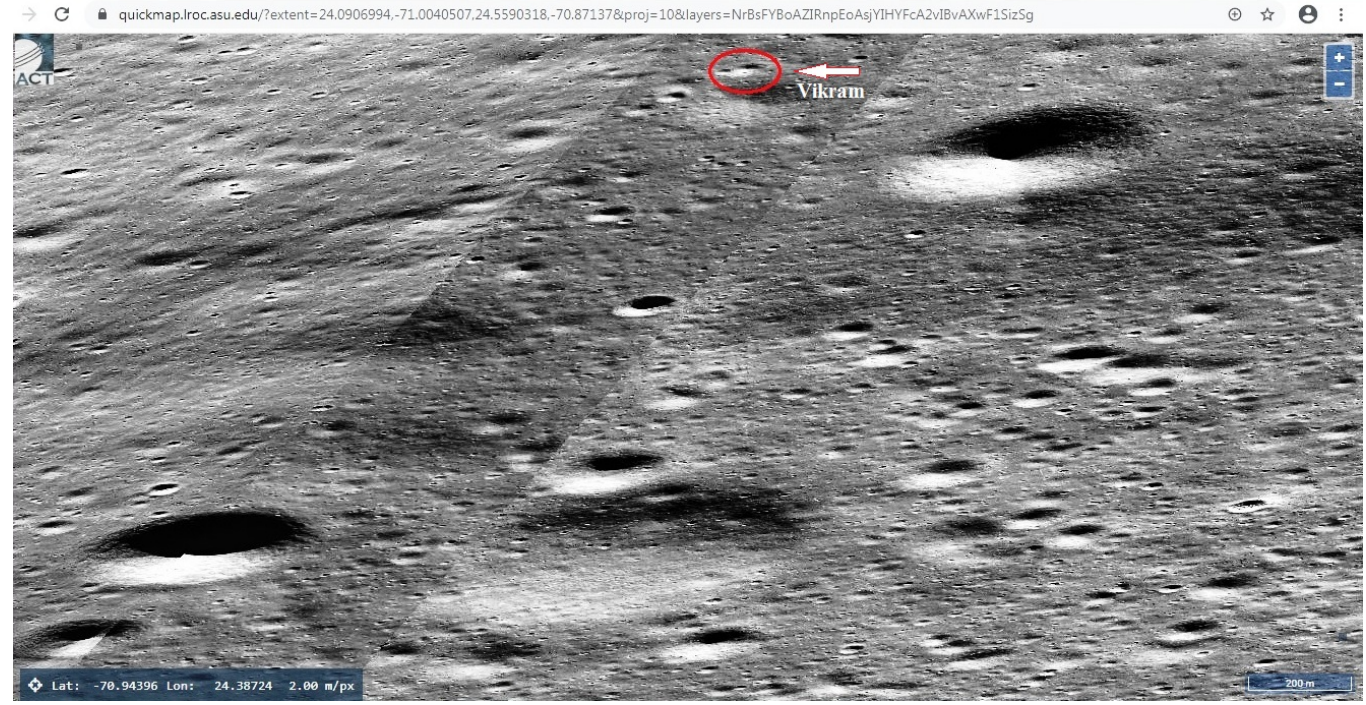

Figure 2: Two big craters (bottom left and top right) form the landmark to the location of the Lunar Lander Vikram

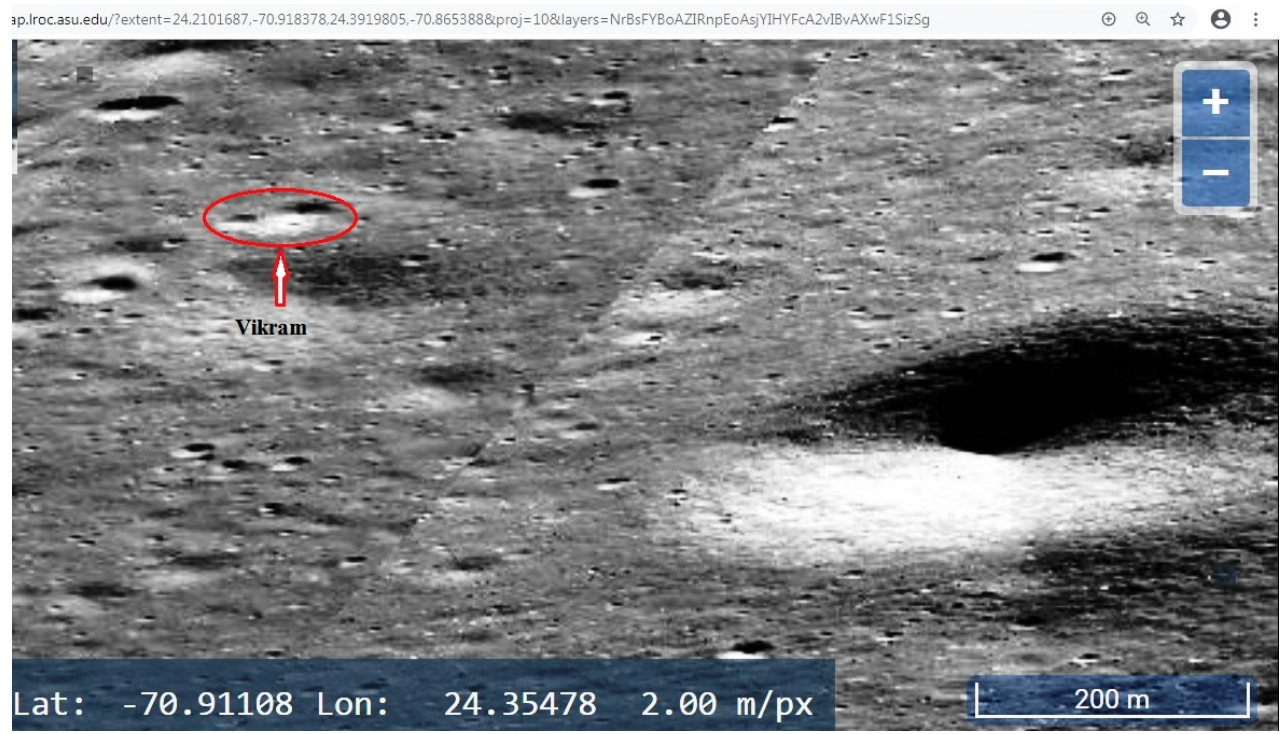

Figure 3: A closer view of the location of Vikram on the left of a big crater

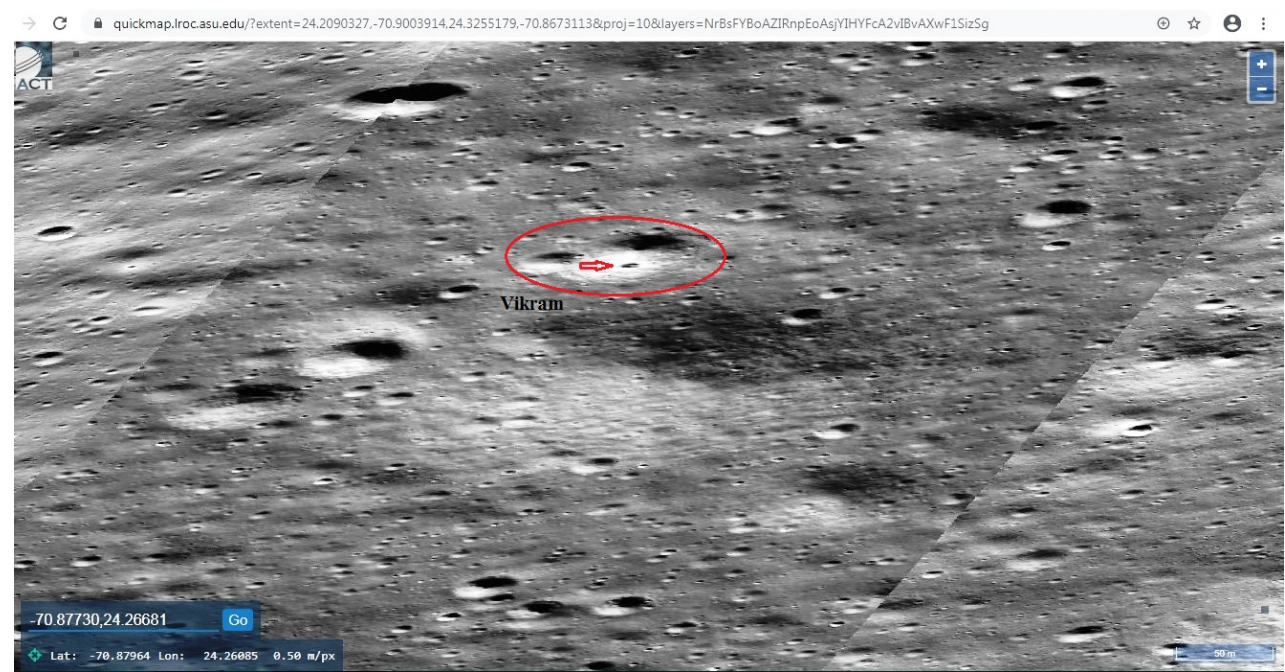

Figure 4: A view of the Lunar Lander Vikram spotted at the actual landing site on the Moon 
The Lost Indian Chandrayaan 2 Lander Vikram and Rover Pragyaan Found Intact in Single Piece on The Moon

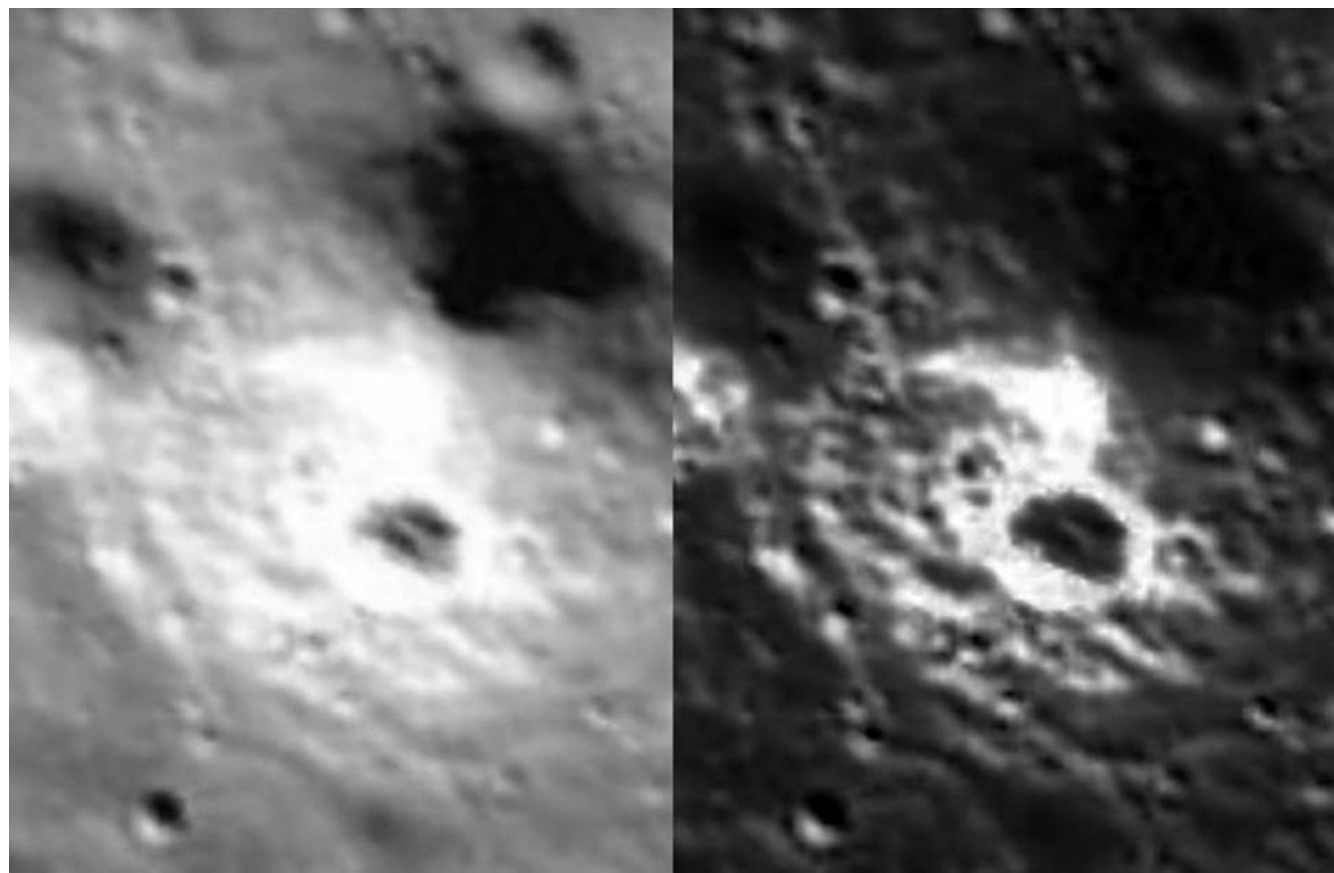

Figure 5: (a) Tilted Vikram seen on the Moon (b) Dehazed image of tilted Vikram at the site

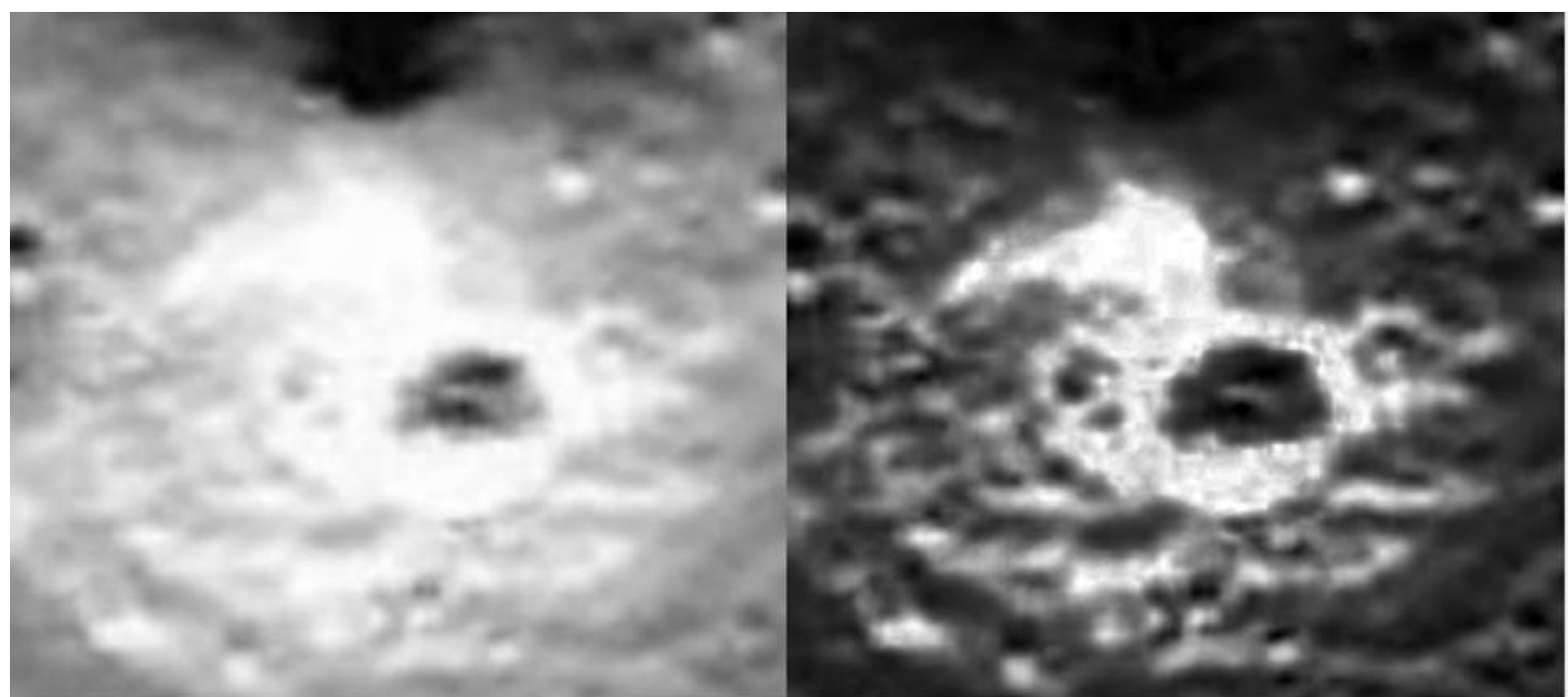

Figure 6: (a) Vikram as seen on the site at Moon (b) Vikram at the site after dehazing its image

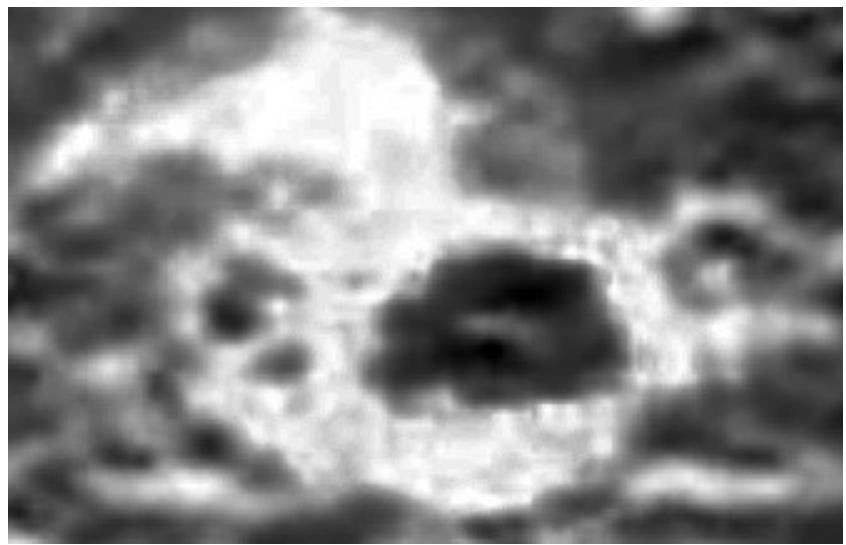

Figure 7: (a) Close up of dehazed image of Vikram

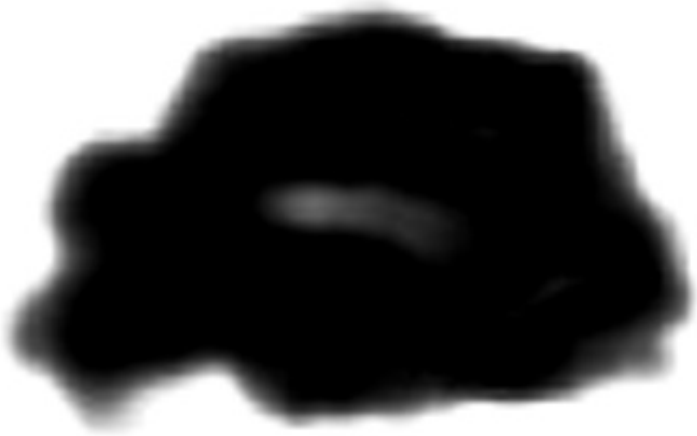

(b) Enlarged view of the dehazed image 


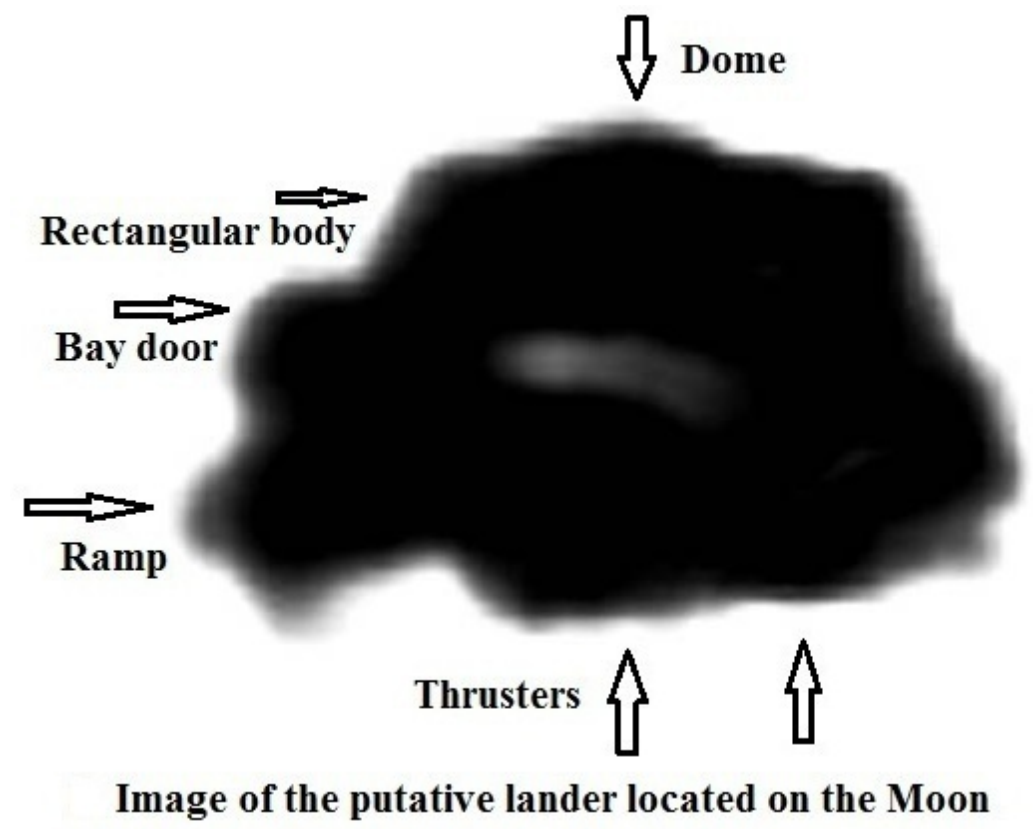

Figure 8: Parts of the object located on the Moon labeled by comparing with a photo of a replica of Vikram

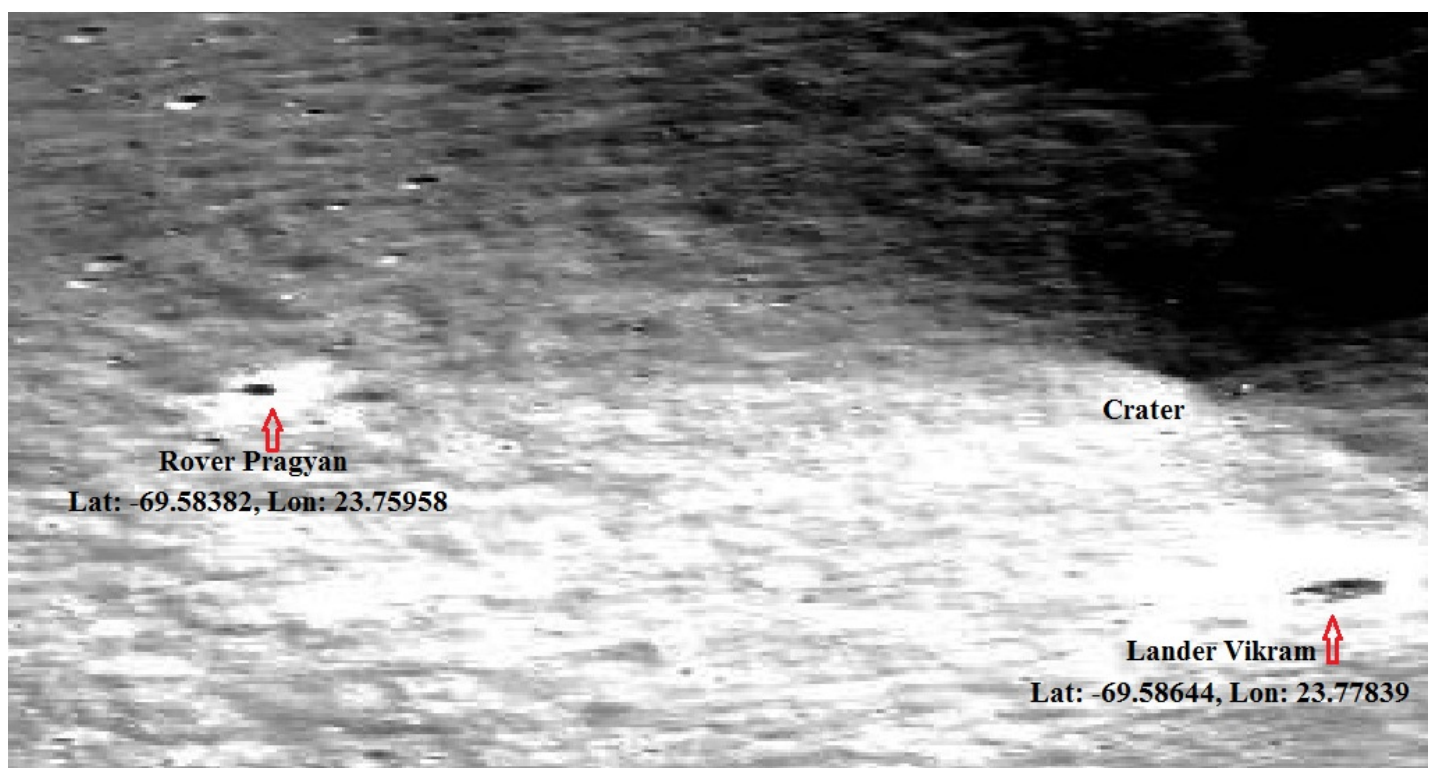

Figure 9: Image of the lander and rover on lunar surface identified from LROC imagery on 1 Sep.2020
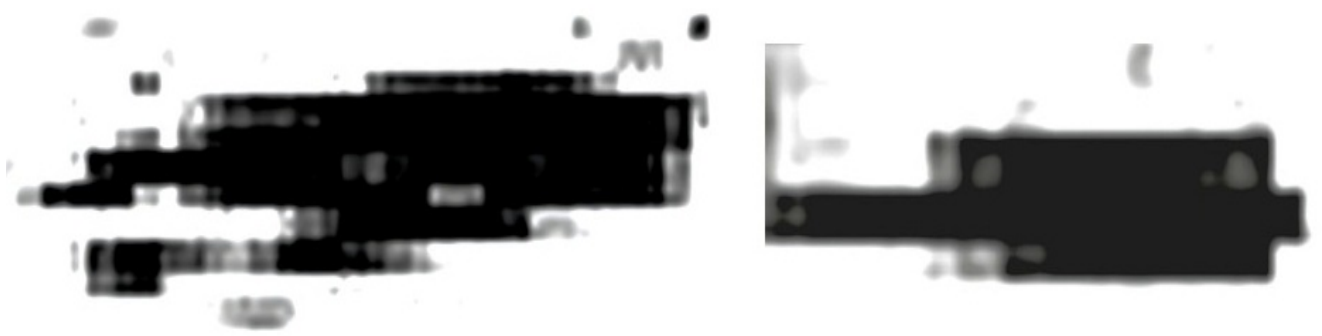

Figure 10: Dehazed and enlarged images of the Lunar Lander Vikram (left) and Rover Pragyaan (right) as seen on 1 September, 2019. 


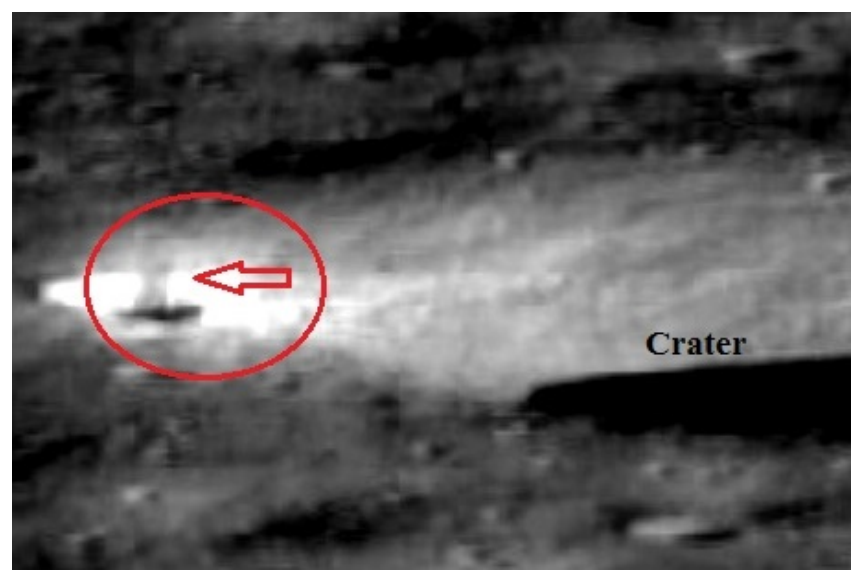

Figure 11: Vertical column of smoke, water or regolith emanating near the site of landing of the lander Vikram.

Earlier, an amateur had claimed to have located the debris about 750 meters northwest of the main crash site as a single bright pixel from the LRO images acquired on 17th September, 2019. Scouring the images acquired by the LRO camera on Oct. 14 and 15 and November 11, 2019, the LROC team of NASA reported the impact site and associated debris field at $70.8810^{\circ} \mathrm{S}, 22.7840^{\circ} \mathrm{E}$ at $834 \mathrm{M}$ elevation [3].

We have obtained clear cut images of the putative Lunar Lander Vikram on the lunar surface at a location close to the scheduled landing site on the South Pole of the Moon. The image has remarkable similarities with the Lander Vikram as we could identify even some structural features of the lander on the image. This sighting puts to rest all speculations about its destruction during landing due to high velocity impact on the lunar surface leading to scattering of the debris to long distances.

\section{CONCLUSIONS AND RECOMMENDATIONS}

The images presented here by us suggest that not only the lander landed successfully on the lunar surface without major destruction, it successfully opened the bay door and deployed the ramp for the release of the rover and its payload. This is contrary to the earlier claims that the lander crashed on the lunar surface due to high speed collision leading to its fragmentation and spread of debris to long distances. However, our findings are in consonance with the ISRO claim of $8^{\text {th }}$ September, 2019 [4] that the lander was intact and in single piece but in a tilted position. We present here for the first time a picture of the lander in a tilted position on the lunar surface.

It is hoped that the present findings will help in locating the lost lander and the rover, identifying the causes of failure of its functioning and efforts to re-establish communication of the orbiter and mission control with the lunar lander and the rover.

\section{SOURCES OF FUNDING}

This research received no specific grant from any funding agency in the public, commercial, or not-for-profit sectors.

\section{CONFLICT OF INTEREST}

The author have declared that no competing interests exist.

\section{ACKNOWLEDGMENT}

The authors are thankful to Prof. Mark Robinson, University of Arizona, USA for providing some files of LROC imagery. 


\section{REFERENCES}

[1] Crane, L. (2019) India's Vikram moon lander appears to have crashed on the moon. New Scientist 14 Sep. 2019 issue 3247. https://www.newscientist.com/article/2215704-indias-vikram-moon-lander-appears-tohave-crashed-on-the-moon/\#ixzz6W7XsK8IG https://www.newscientist.com/article/2215704-indiasvikram-moon-lander-appears-to-have-crashed-on-themoon/\#: :text=0n\%206\%20September\%2C\%20India's\%20Vikram,spacecraft\%20faced\%20a\%20similar \%20fate.\&text=The\%20mission\%20also\%20includes\%20an,was\%20carried $\% 20$ inside $\% 20$ the $\% 20$ lander.

[2] LROC (2020) https://quickmap.lroc.asu.edu/?extent=-90,26.2886793,90,26.2886793\&proj=10\&layers=NrBsFYBoAZIRnpEoAsjYIHYFcA2vIBvAXwF1SizSg

[3] Hille, K. (2019) Vikram Lander Found. NASA 3 Dec. 2019 https://www.nasa.gov/imagefeature/goddard/2019/vikram-lander-found

[4] H T Correspondent (2020) ISRO's Vikram lander lying tilted on moon, but in one piece. The Hindustan Times 27 June 2020. https://www.hindustantimes.com/india-news/isro-s-vikram-lander-lying-tilted-on-moonbut-in-one-piece/story-te7esihMhCv1BmeVfYWv7H.html 